\title{
A novel microsatellite polymorphism in the human $O B$ gene: a highly polymorphic marker for linkage analysis
}

\author{
M. Shintani, H. Ikegami, E. Yamato, Y. Kawaguchi, T. Fujisawa, Y. Nakagawa, Y.Hamada, H. Ueda, T. Miki, \\ T. Ogihara \\ Department of Geriatric Medicine, Osaka University Medical School, Osaka, Japan
}

\begin{abstract}
Summary The mouse $o b$ gene and its human homologue $O B$ have recently been cloned. The mutations in the $o b$ gene are known to be associated with extreme obesity. The relationship between the human $O B$ gene and disease, however, is largely unknown due to the lack of suitable markers within or adjacent to the $O B$ gene. To obtain informative markers, we searched for simple tandem repeat polymorphisms in the genomic sequence of the human $O B$ gene and identified a novel tetranucleotide repeat in the $3^{\prime}$ flanking region. Fifteen alleles were detected in this marker with a heterozygosity of 0.85 and polymorphism information content of 0.83 , indicating a highly informative nature of this marker. Two-point linkage mapping in two Centre Etude Polymorphisme Humaine (CEPH) reference families suggested that this marker is located in the interval between D7S514 and D7S530, the same interval where
\end{abstract}

the $O B$ gene is located (recombination fractions with D7S514 and D7S530 were 0.026 and 0.034 , respectively). Although allele frequency distributions of this marker did not differ between 84 control subjects and 69 NIDDM patients, there was a tendency to higher body weight in control subjects with class I/ class I genotype than in those without this genotype $(68.8 \pm 11.1$ vs $60.8 \pm 10.3 \mathrm{~kg}, p=0.05)$. The highly polymorphic nature of this marker and its location in the $O B$ gene makes this marker useful for linkage studies of the $O B$ gene with a number of phenotypes, such as obesity, non-insulin-dependent diabetes mellitus, hypertension and the insulin resistance syndrome. [Diabetologia (1996) 36: 1398-1401]

Keywords $O B$ gene, microsatellite, genetics, obesity, diabetes mellitus.
Non-insulin-dependent diabetes mellitus (NIDDM) is a complex metabolic disorder with a significant genetic component [1]. Obesity is a frequent complicating factor that increases the risk of diabetes. The multifactorial nature of obesity, however, makes it difficult to genetically dissect obesity and related diseases; therefore, genetically obese animals are useful, and several models of obesity have been established

Received: 9 July 1996 and in revised form: 7 August 1996

Corresponding author: Dr. H. Ikegami, Department of Geriatric Medicine, Osaka University Medical School, 2-2 Yamadaoka, Suita, Osaka 565, Japan

Abbreviations: PCR, Polymerase chain reaction; PIC, polymorphism information content; LOD, logarithm of odds; NIDDM, non-insulin-dependent diabetes mellitus. in rodents. In the mouse, a number of single gene defects that result in obesity have been described. $\mathrm{Mu}-$ tations in one of these genes, the $o b$ gene, result in both obesity and NIDDM [2]. Recently, the murine $o b$ gene and its human homologue have been cloned. A mutation causing a premature stop codon or the total absence of $o b$ mRNA results in obesity in $o b / o b$ mice [2]. The specific role of genetic factors in the regulation of body weight and the identity of such factors are not well defined in humans [3, 4].

The human $O B$ gene consists of three exons and two introns and spans about 18 kilobase pairs $(\mathrm{kb})$, encoding a 3.5-kb mRNA [5]. Although polymorphisms or mutations in the human $O B$ gene associated with obesity and/or diabetes have not yet been identified $[3,4,6]$, it is reasonable to speculate that mutations in the $O B$ gene could result in obesity in 


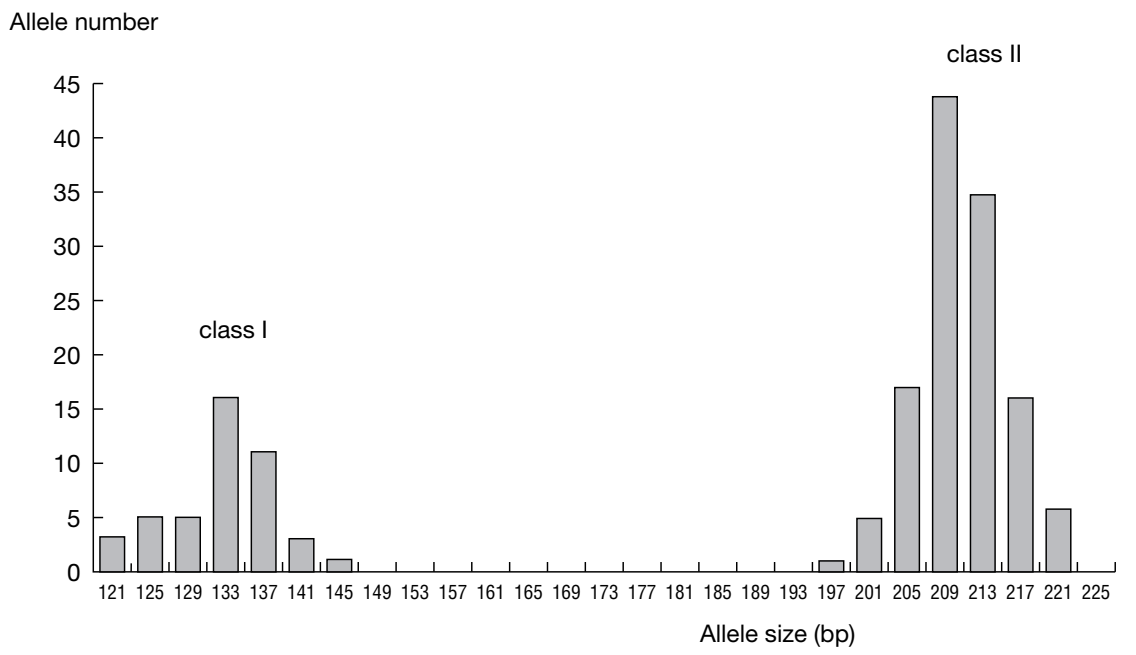

Fig. 1. Distribution of alleles of microsatellite polymorphism in the $O B$ gene in control subjects

humans. In fact, plasma leptin levels have been reported to correlate positively with BMI and body fat percentage in humans [7].

To examine the relationship between the $O B$ gene and the pathogenesis of obesity, we searched for a polymorphic marker in the $O B$ gene and identified a novel microsatellite marker in the $3^{\prime}$ flanking region of the human $O B$ gene. Using this newly found marker we investigated the association of the microsatellite marker polymorphism with NIDDM and obesity.

\section{Materials and methods}

We studied 153 unrelated Japanese subjects (69 with NIDDM and 84 control subjects); informed consent was obtained from each subject. NIDDM patients (25 females and 44 males) were diagnosed according to the World Health Organization criteria and were under treatment at the outpatient clinic of the Osaka University Medical Hospital. Modes of treatment were: insulin therapy $32 \%$, oral hypoglycaemic agents $46 \%$, and diet alone $22 \%$. Control subjects consisted of 28 females and 56 males with normal glucose tolerance.

From published genomic DNA sequences of the human $O B$ gene (accession number: D63708), we searched for simple tandem repeats (or microsatellites). A tetranucleotide repeat polymorphism was identified in the $3^{\prime}$ flanking region of the $O B$ gene. A set of primers was synthesized to amplify the tetranucleotide repeats by the polymerase chain reaction (PCR). Primer sequences were: HOBF, 5'-AGT TCA AAT AGA GGT CCA AAT CA (forward primer) and HOBR, 5'-TTC TGA GGT TGT GTC ACT GGC A (reverse primer). PCR reactions included $100 \mathrm{ng}$ genomic DNA template, $0.2 \mu \mathrm{mol} / 1$ of each primer, $2.0 \mathrm{mmol} / 1 \mathrm{Mg}^{2+}, 0.8 \mathrm{mmol} / 1$ each dNTP, $1.5 \mathrm{U}$ Taq-polymerase (Perkin Elmer, Branchburg, N.J., USA) and reaction buffer in a total volume of $10 \mu \mathrm{l}$. The PCR reactions were performed for 35 cycles of $30 \mathrm{~s}$ at $94^{\circ} \mathrm{C}, 30 \mathrm{~s}$ at $54^{\circ} \mathrm{C}$, and $1 \mathrm{~min}$ at $72^{\circ} \mathrm{C}$, with an initial denaturation of $3 \mathrm{~min}$ at $94^{\circ} \mathrm{C}$ and a final extension of $10 \mathrm{~min}$ at $72^{\circ} \mathrm{C}$. PCR products were run in $9 \%$ polyacrylamide gel along with pBR322 DNAMspl digest (New England Biolabs, Beverly, Mass., USA) as a molecular weight marker. Amplified products were visualized by staining with ethidium bromide.

To confirm that the detected bands were the products of expected sequences, each allele was subcloned into pT7 vector and the sequence of each allele was determined by ABI $373 \mathrm{~S}$ sequencer (Perkin Elmer, Foster City, Calif., USA).

Two reference families $(1347,1416)$ in the Centre Etude Polymorphism Humaine (CEPH) linkage database were genotyped with this microsatellite marker. Two-point linkage analysis between this marker and others in the CEPH database (version 7) was performed using LODSCORE and MLINK programs of the LINKAGE package (version 5.1).

\section{Statistical analysis}

Results are given as mean \pm SD. Differences between group means were tested by Student's $t$-test. Chi-square test or Fisher's exact test was used to compare the frequencies.

\section{Results}

Overall, 15 alleles were found for this marker, with a heterozygosity of 0.85 and a polymorphism information content (PIC) of 0.83 . Histograms of the allele distribution suggested that the alleles were composed of two groups with different size distribution (Fig.1). Alleles were therefore classified into two groups: the shorter one (termed class I) and the longer one (termed class II). The existence of two groups of alleles with distinct size distribution was confirmed by sequencing of the respective alleles from each group. For example, sequencing of alleles from a heterozygote I-4/II-5 revealed that I-4 consists of 12 repeats and II-5 consists of 30 repeats.

Mendelian inheritance was confirmed in the families studied. Two-point linkage mapping in CEPH families suggested that this marker is located in the interval between D7S514 and D7S530, the same interval in which the $O B$ gene is located. The 
Table 1. Distribution of $O B$ alleles in subgroups of control subjects and NIDDM patients divided by BMI

\begin{tabular}{|c|c|c|c|c|c|c|}
\hline \multirow[b]{2}{*}{ Alleles (n) } & \multicolumn{3}{|c|}{ Control subjects } & \multicolumn{3}{|c|}{ NIDDM patients } \\
\hline & $\begin{array}{l}\text { lower BMI } \\
84\end{array}$ & $\begin{array}{l}\text { higher BMI } \\
84\end{array}$ & Total & $\begin{array}{l}\text { lower BMI } \\
70\end{array}$ & $\begin{array}{l}\text { higher BMI } \\
68\end{array}$ & Total \\
\hline $\begin{array}{l}\text { class II } \\
\text { II-1 [197bp] } \\
\text { II-2 [201bp] } \\
\text { II-3 [205bp] } \\
\text { II-4 [209bp] } \\
\text { II-5 [213bp] } \\
\text { II-6 [217bp] } \\
\text { II-7 [221bp] } \\
\text { II-8 [225bp] }\end{array}$ & $\begin{array}{c}1(1.2) \\
4(4.8) \\
9(10.7) \\
25(29.8) \\
19(22.6) \\
6(7.1) \\
3(3.6) \\
0(0.0)\end{array}$ & $\begin{array}{c}0(0.0) \\
1(1.2) \\
8(9.5) \\
19(22.6) \\
16(19.0) \\
10(11.9) \\
3(3.6) \\
0(0.0)\end{array}$ & $\begin{array}{c}1(0.6) \\
5(3.0) \\
17(10.1) \\
44(26.2) \\
35(20.8) \\
16(9.5) \\
6(3.6) \\
0(0.0)\end{array}$ & $\begin{array}{c}0(0.0) \\
4(5.7) \\
6(8.6) \\
18(25.8) \\
15(21.4) \\
4(5.7) \\
1(1.4) \\
0(0.0)\end{array}$ & $\begin{array}{c}0(0.0) \\
1(1.5) \\
8(11.8) \\
19(27.9) \\
14(20.6) \\
5(7.4) \\
0(0.0) \\
2(2.9)\end{array}$ & $\begin{array}{c}0(0.0) \\
5(3.6) \\
14(10.2) \\
37(26.8) \\
29(21.0) \\
9(6.5) \\
1(0.7) \\
2(1.5)\end{array}$ \\
\hline $\begin{array}{l}\text { class I total } \\
\text { class II total }\end{array}$ & $\begin{array}{l}17(20.2) \\
67(79.8)\end{array}$ & $\begin{array}{l}27(32.2) \\
57(67.8)\end{array}$ & $\begin{array}{r}44(26.2) \\
124(73.8)\end{array}$ & $\begin{array}{l}22(31.4) \\
48(68.6)\end{array}$ & $\begin{array}{l}19(27.9) \\
49(72.1)\end{array}$ & $\begin{array}{l}41(29.7) \\
97(70.3)\end{array}$ \\
\hline
\end{tabular}

Data are number of alleles with (\%)

recombination fraction between D7S514 and the marker was 0.026 with a logarithm of odds (LOD) score of 9.43. The recombination fraction between D7S530 and the marker was 0.034 with LOD score of 6.84 .

Allele frequency of $O B$ allele in control and NIDDM patients: The allele frequency distribution was similar in the control subjects and NIDDM patients (Table 1). Because of the well-known contribution of the $o b$ gene to obesity, control subjects and NIDDM patients were divided into two groups according to their BMI so that each group contained the same number of subjects (lower BMI and higher BMI groups). In control subjects, the frequency of I-4 allele and class I alleles was slightly, but not significantly, higher in the higher BMI group than in the lower BMI group (I-4 allele: 15.5 vs $7.1 \%$, odds ratio $2.4, p=0.07$; class I alleles: 32.1 vs $20.2 \%$, odds ratio $1.9, p=0.07$, Table 1$)$. When the subjects were divided into non-obese $(n=148)$ and obese $(n=20)$ groups according to the criteria of the National Diabetes Data Group, the frequency of class I alleles was slightly, but not significantly, higher in the obese group than in the non-obese group (35 vs $25 \%$ ).

To examine the relationship between clinical characteristics of the subjects and genotypes of the $O B$ gene, subjects were divided into three groups according to their genotype: class I/class I, class I/class II, class II/class II. In the control subjects, there was a tendency for higher body weight and BMI in subjects with class I/class I genotype than in those without this genotype (body weight: $68.8 \pm 11.1$ vs $60.8 \pm 10.3 \mathrm{~kg}$, $p=0.05 ; \quad$ BMI: $\quad 24.0 \pm 3.3 \quad$ vs $\quad 22.2 \pm 2.7 \mathrm{~kg} / \mathrm{m}^{2}$, $p=0.09)$. No significant differences were observed in fasting plasma glucose, $\mathrm{HbA}_{1 \mathrm{c}}$, age-at-onset of diabetes, or BMI in NIDDM patients with different genotypes (data not shown).

\section{Discussion}

Obesity is one of the major risk factors for a number of chronic diseases including NIDDM, hypertension, and ischaemic heart disease. Recently, the murine $o b$ gene and the human homologue, $O B$, were cloned and characterized [2]. Mutation in the $o b$ gene results in severe obesity in $o b / o b$ mice [2]. While no mutations have yet been reported in the coding region of the human $O B$ gene, Karine et al. [8] genotyped siblings in 78 families at markers flanking the human $O B$ gene and demonstrated that some individuals with extreme obesity (BMI $\geq 40 \mathrm{~kg} / \mathrm{m}^{2}$ ) had an allelic variant of the $O B$ gene, suggesting that variation in the $O B$ gene may be one cause of genetically determined obesity in human populations. Clement et al. [9] genotyped eight microsatellite markers spanning the $O B$ gene region in obese French families and reported evidence suggestive of linkage of obesity with three markers located about $2 \mathrm{cM}$ from the $O B$ gene. These data suggest that the $O B$ gene is a candidate for genetic predisposition to obesity in a subset of families. Lack of informative markers within or adjacent to the $O B$ gene, however, has hampered further analysis. To obtain such markers, we searched for genomic sequences of the $O B$ gene and identified a microsatellite composed of tetranucleotide repeats $157 \mathrm{bp}$ downstream of the end of the last exon of the 
$O B$ gene. PCR analysis of the microsatellite revealed that this marker is highly polymorphic and informative with a heterozygosity of 0.85 and a PIC of 0.83 .

Using the newly identified microsatellite marker, we analysed the association of the $O B$ polymorphism with NIDDM and obesity. No significant difference in the distribution of alleles and genotypes was found between NIDDM patients and control subjects. In control subjects, however, the frequency of class I allele was higher in the higher BMI group than in the lower BMI group, although the difference did not reach statistical significance (odds ratio 1.9, $p=0.07$ ). Furthermore, there was a tendency for higher body weight in subjects with class I/class I genotype than in those without this genotype $(68.8 \pm 11.1$ vs $60.8 \pm 10.3 \mathrm{~kg}, p=0.05)$, suggesting that class I alleles may be associated with higher body weight. Recent reports in Caucasians suggest that extreme obesity may be linked to markers flanking the human $O B$ gene $[8,9]$. Due to the low frequency of extreme obesity in the Japanese, we could not study its association with the new marker. Since the microsatellite marker we identified is much closer than the markers used in previous reports, it will provide a powerful and useful tool for genetic linkage and association studies between the $O B$ gene and a number of phenotypes such as obesity, NIDDM, hypertension and the insulin resistance syndrome in different ethnic groups.

One of the unique characteristics of this microsatellite is the allele size distribution with two distinct size classes (Fig. 1). Two classes of alleles have also been observed in French subjects from CEPH reference families, suggesting that both exist in both Japanese and Caucasian populations. Studies of allele distributions in different ethnic groups will clarify the evolution of the $O B$ gene region as well as the relative contribution of different classes of alleles to a number of phenotypes, including diabetes, obesity and the insulin resistance syndrome. The existence of different size classes of alleles has been reported for a variable number of tandem repeat (VNTR) polymorphism $5^{\prime}$ to the insulin gene (INS VNTR) [10] and triplet repeat polymorphisms in genes responsible for several genetic diseases, such as myotonic dystrophy. A difference in the size classes of the INS VNTR was reported to affect the transcription of the insulin gene [10]. The existence of different size classes of alleles, together with its location in the $3^{\prime}$ flanking region of the $O B$ gene, suggest that this polymorphism may directly affect the expression of the $O B$ gene. We are currently studying the relationship between serum leptin level and the $O B$ genotypes.

In conclusion, we have identified a highly polymorphic tetranucleotide repeat polymorphism in the $3^{\prime}$ flanking region of the $O B$ gene. This marker will be useful in future genetic studies on the linkage and association of the human $O B$ gene with a number of phenotypes such as obesity and NIDDM.

Acknowledgements. We thank Ms. Y. Ueno for her skillful technical support. This work was supported in part by a Grant for Diabetes Research from the Ministry of Health and Welfare, a Grant-in-Aid of the Japan Medical Association, a Grant from the Sandoz Foundation for Gerontological Research, a Mitsukoshi Grant-in-Aid, and a Grant from Otsuka Pharmaceutical Co.

\section{References}

1. Ghosh S, Nicholas J (1996) Genetic analysis of NIDDM. Diabetes 45: 1-14

2. Zhang Y, Proenca R, Maffei M, Barone M, Leopold L, Friedman JM (1994) Positional cloning of the mouse obese gene and its human homologue. Nature 372: 425-432

3. Considine RV, Considine EL, Williams CJ et al. (1995) Evidence against either a premature stop codon or the absence of obese gene mRNA in human obesity. J Clin Invest 95: 2986-2988

4. Margherita M, Markus S, Marisa B et al. (1996) Absence of mutations in the human $O B$ gene in obese/diabetic subjects. Diabetes 45: 679-682

5. Naohi I, Yoshihiro O, Naohisa T et al. (1995) Structural organization and chromosomal assignment of the human obese gene. J Biol Chem 46: 27728-27733

6. Toshiharu N, Hiroyuki M, Yoshikazu Tet al. (1996) Molecular screening in Japanese and Asian Indian NIDDM patients associated with obesity. Diabetes 45: 675-678

7. Samuel DJ, Carmine F, Deanna P, Joy B, Michael L (1996) Plasma leptin and insulin relationships in obese and nonobese humans. Diabetes 45: 695-698

8. Karine C, Chad G, Jorg H et al. (1996) Indication for linkage of the human $O B$ gene region with extreme obesity. Diabetes 45: 687-690

9. Danielle RR, Yuan D, Weizhen X, Corinne C, Eric DG, Price RA (1996) Extreme obesity may be linked to markers flanking the human $O B$ gene. Diabetes 45: 691-694

10. Kennedy GC, German MS, Rutter WJ (1995) The minisatellite in the diabetes susceptibility locus IDDM2 regulates insulin transcription. Nat Genet 9: 293-298 